\title{
TEORÍA DEL ÓRGANO Y RESPONSABILIDAD PÚBLICA EN LA LEY DE BASES DE LA ADMINISTRACIÓN DEL ESTADO*
}

\author{
José Miguel Valdivia Olivares**
}

\begin{abstract}
RESUMEN
El recurso persistente a la teoría del órgano administrativo para resolver cuestiones de responsabilidad pública aconseja revisar esa teoría. Una reconstrucción dogmática de esa teoría permite apreciar su complejidad y sus limitaciones para explicar la forma en que la responsabilidad del Estado puede verse comprometida. Sin suministrar reglas de responsabilidad, la teoría se muestra incapaz de justificar los regimenes ni la extensión que asume la responsabilidad pública, conforme a la ley. Prefiriendo un enfoque funcional, el estudio propone prescindir de esta teoría para enfrentar esta clase de problemas.

\author{
ÓRGANO DEL ESTADO - RESPONSABILIDAD DEL ESTADO - \\ RESPONSABILIDADES DIRECTA E INDIRECTA
}

\section{The "theory of the public agency" and the state liability in the Chilean Government Administration Framework Act}

Abstract

The persistent use of the "theory of the public agency" to resolve matters of state liability makes it advisable to review that theory. A dogmatic reconstruction of that theory reveals its complexity and limitations in explaining the way in which the liability of the State may be compromised. Without providing rules on liability, the theory proves incapable of justifying the regime of state liability under the law. Preferring a functional focus, the study proposes to discard the theory in order to solve this type of problems.
\end{abstract}

\section{PUBLIC AGENCIES - STATE LIABILITY - DIRECT AND INDIRECT LIABILITIES}

\footnotetext{
* Estas notas surgen de reflexiones vinculadas con la investigación desarrollada por el autor en el marco de su tesis doctoral (en preparación) sobre Une lecture française du régime cbilien de responsabilité de la puissance publique, bajo la dirección del profesor Yves Gaudemet.

** Abogado. Máster en Derecho Público. Profesor de Derecho Administrativo de la Universidad Adolfo Ibáñez, Santiago de Chile. Correo electrónico: jmvaldivia@blc.cl. Artículo recibido el 30 de septiembre de 2006 y aceptado para su publicación por el Comité Editorial el 6 de noviembre de 2006.

Abreviaciones usuales: CA: fallo de una Corte de Apelaciones; chr.: crónica; col.: colección; concl.: conclusiones (de los comisarios del gobierno); conf.: confirmado (o, según el caso, desestimados los recursos en su contra); cons.: considerando; CS: fallo de la Corte Suprema; FM: Fallos del Mes; GJ: Gaceta Jurídica; IusP: Revista Ius Publicum; JL: fallo de un juzgado de letras (JLCiv: juzgado civil; JLCri: juzgado del crimen); Ley de Bases: Ley de Bases Generales de la Administración del Estado, $\mathrm{N}^{\circ} 18.575$, refundida por DFL N ${ }^{\circ}$ 1-19653, del Ministerio Secretaría General de la Presidencia; LGDJ: Librairie générale de législation et de jurisprudence; LN: Base de datos Lexis Nexis; M.: Municipalidad; n.: nota (de jurisprudencia); RDJ: Revista de Derecho y Jurisprudencia; RDP-UCh: Revista de derecho público (Universidad de Chile); repr.: reproducido; SS: Servicio de Salud.
} 


\section{INTRODUCCIÓN}

1. $\mathrm{n}$ un reciente fallo Caro Silva (de 19 de octubre de 2005) la Corte Suprema dice que "la teoría del órgano se limita a constatar para hacer nacer la responsabilidad extracontractual del Estado, si el daño ha sido causado a consecuencia de la actuación, la omisión, del retardo o del funcionamiento parcial de un servicio, excluyendo del análisis si el daño resultante es imputable a culpa o negligencia del funcionario público". ${ }^{1}$ Tal frase no es original. Está tomada del libro Sujetos de la acción de responsabilidad extracontractual de José Bidart, ${ }^{2}$ que la Corte cita expresamente. Ella tampoco era estrictamente necesaria para la resolución del asunto. El daño había sido ocasionado por un agente del Estado en ejercicio de sus funciones, de modo que la aplicación literal del art. 4 de la Ley de Bases hacía innecesario todo esfuerzo de teorización. La referencia a la teoría del órgano en ese fallo podría dar lugar a reflexiones más profundas. De hecho, conduce a una confusión entre el órgano y el servicio que parece poco ortodoxa. Baste por el momento retener la persistencia del argumento.

La teoría del órgano ha sido, aparentemente, objeto de aplicación y reflexión judicial en algunos asuntos más o menos delicados de responsabilidad pública. ${ }^{3}$ No forma parte de los útiles cotidianos del juez de la administración, pero su uso, esporádico, es persistente. Desde hace casi treinta años se cree en el medio chileno que la teoría puede ser de alguna utilidad en el contencioso de la responsabilidad pública. Aparentemente, este estado de cosas es resultado de un artículo de doctrina aparecido en 1979 en la Revista de Derecho público de la Universidad de Chile. ${ }^{4}$

Con todo, si se analizan los pocos desarrollos doctrinales sobre la materia, da la impresión que el impacto de esta construcción filosófico-jurídica en esta materia ha sido débil. La teoría nunca ha sido objeto de análisis serio en el medio nacional, al punto que sería tentador preguntarse si los jueces entienden de qué hablan cuando hablan de órganos.

El presente análisis tiene un objeto aún más modesto, que consiste en determinar si la Ley de Bases Generales de la Administración del Estado ha recogido la teoría del órgano, a propósito de la responsabilidad.

2. Las razones de esta restricción del campo de estudio pueden parecer inocentes. La opinión común indica que la Ley de Bases es una ley técnica, elaborada gracias al saber

\footnotetext{
${ }^{1}$ CS, 19.10.2005, Caro Silva d Fisco, GJ N ${ }^{\circ}$ 304, 2005, p. 70. En el mismo sentido, CS, 20.03.2006, Vargas Grandón cl García Hernández, GJ No 309, 2006, 59.

${ }^{2}$ Jurídica, Santiago, 1985, p. 207.

${ }^{3}$ Según Claudio Illanes, la primera sentencia nacional que habría acogido la teoría del órgano corresponde a CA Santiago, 26.01.1984, Banco Continental c/ Bahamondes y otros, RDJ No 81, 1984, II, $2^{\mathrm{a}}$, p. 11 (redactada por el autor). "Responsabilidad civil del Estado y de sus dependientes", Revista de Derecho-U. Católica del Norte $\mathrm{N}^{\circ}$ 6, 1999, p. 7.

${ }^{4}$ Caldera, H., "Teoría del órgano, Estado de derecho y responsabilidad del Estado: notas sobre su formulación en el derecho chileno”, $R D P-U C b \mathrm{~N}^{\circ} 25-26,1979$, p. 157 s. Ese análisis fue reproducido casi literalmente en su Sistema de la responsabilidad extracontractual del Estado en la Constitución Política de 1980, Jurídica, Santiago, 1982, p. 190 s.
} 
técnico de diversos especialistas conocedores del derecho público y de la ciencia administrativa. Es por ese carácter de la Ley de Bases que debería encontrarse en ella las trazas de la teoría del órgano. Al analizar sin embargo el significado de la voz "órgano" en la Ley de Bases, es difícil hallar en ella resultados concluyentes. Ante todo, la ley no entrega una definición legal del órgano. Da, en cambio, respuestas bastante contradictorias al respecto. Por una parte, parece distinguir entre "órganos" y "servicios públicos" (arts. 1, 24, 46, 49), pero esa no es una distinción auténtica, pues los servicios públicos también han sido concebidos como órganos, ${ }^{5}$ incluso como entidades dotadas de órganos. ${ }^{6}$ La ley parece atribuir la calidad de órgano a la autoridad de la cual emana cierto acto administrativo (art. 10$),{ }^{7}$ pero en seguida confiere la misma calidad a instituciones administrativas enteras, de un tamaño bastante variable, sin importar tampoco que gocen o no de personalidad jurídica (art. 21). ${ }^{8}$ Así, las Fuerzas Armadas, carentes de personalidad propia, están en el mismo pie que las "empresas públicas", que sí son personificadas. Los funcionarios, en cambio, excepto aquellos a quienes la ley atribuye directamente el carácter de "órganos" (como los Ministros de Estado, art. 22), "sólo podrán ser destinados a funciones propias del empleo para el cual han sido designados, dentro del órgano o servicio público correspondiente” (art. 46, inc. 3). La expresión "órgano" carece pues de toda precisión técnica, confundiéndose a menudo con aquella de "organismo" (igualmente sin definir).

Parece bastante evidente que la expresión órgano no fue utilizada en un sentido demasiado técnico en la Ley de Bases. En cualquier caso, no fue empleada en un sentido unívoco, lo que suscita de entrada dudas en torno a la recepción de la teoría del órgano por esta ley. Pero no vale la pena detenerse en una constatación tan superficial como ésa. La técnica legislativa puede parecer cuestionable, pero no agota el análisis del problema.

3. La teoría del órgano sirve al poder. Tiene por objeto atribuir a un ente público los actos de sus agentes: tal acto ejecutado por un ciudadano $\mathrm{X}$ puede ser imputado o atribuido al Estado sólo en la medida que ese ciudadano pueda ser considerado un órgano del Estado. Despojando la teoría de todo su ropaje pseudobiológico, esa es la conclusión a que condujo el análisis ya clásico de Kelsen, para quien el problema del Estado era ante todo "un problema de imputación", es decir, de definición de las condiciones según las cuales ciertas acciones humanas deben ser consideradas como acciones del Estado. En esta perspectiva, “se llama 'órganos' del Estado a aquellos individuos cuyas

5 “Artículo 28.- Los servicios públicos son órganos administrativos encargados de satisfacer necesidades colectivas, de manera regular y continua”.

${ }^{6}$ Desde que según el art. 33 (inc. final), "La desconcentración funcional se realizará mediante la radicación por ley de atribuciones en determinados órganos del respectivo servicio".

${ }^{7}$ El recurso de reposición puede deducirse, según este artículo, "ante el mismo órgano del que hubiere emanado el acto".

${ }^{8}$ Las instituciones mencionadas en el art. 21 son, en efecto, "órganos que se regirán por las normas constitucionales pertinentes y por sus respectivas leyes orgánicas constitucionales o de quórum calificado, según corresponda”. 
acciones son precisamente consideradas como actos del Estado". 9 La teoría del órgano es, en definitiva, una teoría de imputación; ella determina bajo qué circunstancias el acto de un agente público puede ser imputado al ente público de que se trate. En el terreno de la responsabilidad, esa utilidad inmediata de la teoría debería traducirse en el establecimiento de una responsabilidad directa del ente público (A). Esa vocación inmediata de la teoría conduce a preguntarse sobre la responsabilidad indirecta, o más generalmente sobre la extensión de la responsabilidad pública (B).

\section{A. LA TEORÍA DEL ÓRGANO COMO EXPLICACIÓN} DEL CARÁCTER DIRECTO DE LA RESPONSABILIDAD PÚBLICA

4. La invocación de la teoría del órgano en la doctrina nacional busca obviar las paradojas a que conduce la concepción usual de la personalidad jurídica. En efecto, se dice con frecuencia que el derecho nacional recoge la teoría de la ficción, que fue en alguna ocasión formulada por Savigny. Como el Estado, así como las restantes personas jurídicas de derecho público, no tiene existencia real (recuérdese la broma de Jèze sobre la comida que nunca tuvo con una persona jurídica), es necesario buscar un artificio, igualmente ficticio, para hacerlas responsables. De otro modo resultaría seguramente inaceptable buscar un chivo expiatorio en una persona inexistente, que no puede actuar ni menos incurrir en culpa.

5. Léon Duguit, a pesar de haber sido un detractor célebre de la teoría, expuso en forma clara la manera en que ella hacía posible articular técnicamente la responsabilidad pública. "Esta concepción jurídica del órgano permite también explicar la responsabilidad delictual de las personas corporativas en general y del Estado en particular... [Si] se ve en los agentes de una corporación o del Estado a órganos de la persona colectiva, el acto voluntario de esos órganos es acto voluntario de la persona jurídica; lo que se nos aparece exteriormente como culpa de los agentes es realmente culpa de la corporación o del Estado. Hay pues verdaderamente una voluntad delictual de la persona colectiva; hay responsabilidad personal y directa de la corporación o del Estado. Esta responsabilidad puede incluso ser penal". ${ }^{10}$ Carré de Malberg compartía conceptos análogos ${ }^{11}$ y Léon Michoud (en un estudio bastante antiguo) se orientaba en el mismo sentido. ${ }^{12}$

${ }^{9}$ Kelsen, H., Théorie générale du droit et de l'État, LGDJ-Bruylant, París-Bruselas, trad. B. Laroche, 1997, p. 245. Cf. Troper, M., "Réflexions autour de la théorie kelsenienne de l'État", Pour une théorie juridique de l'État, Presses universitaires de France (col. Léviathan), París, 1994, p. 143 s.

${ }^{10}$ L'État, les gouvernants et les agents, Fontemoing, París, 1903 (reedición Dalloz, París, 2005), p. 35.

${ }^{11}$ Contribution à la théorie générale de l'État. Spécialement d'après les données fournies par le droit constitutionnel français, Sirey, París, 1922 (reedición Dalloz, París, 2004), t. II, § 381, p. 311.

12 "La responsabilité de l'État à raison des fautes de ses agents", en Revue du droit public 1895, p. 401. 
Por medio del artificio del órgano parecen salvadas las dificultades de construcción de una responsabilidad directa de la persona jurídica. Hasta su formulación, en efecto, se concebía la actuación de las personas jurídicas únicamente por medio de los mecanismos clásicos de representación: el mandato, que indudablemente generaba distorsiones al introducir un tercero entre la víctima y la entidad a quien se deseaba hacer responsable. Una imputación perfecta, como la que supone la teoría del órgano, reduce el riesgo de involucrar al agente, pues su acto es por definición un acto de la persona jurídica.

6. La construcción teórica presenta sin embargo limitaciones que reducen su alcance (II); en sí misma, además, reviste una ambivalencia que dificulta darle un sentido único (I).

\section{La ambivalencia de la teoría}

7. Si poseyera una unidad cierta, la teoría del órgano sería quizá una pista útil para imputar responsabilidad a las personas públicas. La complejidad de la teoría, que ha conducido a algunos a proponer prescindir de ella, impide reconocer tal unidad. Las interpretaciones de la doctrina parecen, en efecto, inconciliables: aunque no faltan quienes quieren atribuir carácter de órgano a todos los agentes públicos (b), el sentido originario del órgano es, al contrario, restrictivo (a).

\section{a. Un concepto originariamente restrictivo}

8. Conforme a los orígenes del concepto, la noción de órgano sirve simplemente para dar coherencia a la idea de persona jurídica. El Estado, persona ficticia, no podría tener voluntad propia ni mucho menos expresarla sin el concurso de los órganos. Así, el órgano corresponde eminentemente a las funciones de decisión del aparato estatal: el cuerpo electoral, el Parlamento, los tribunales, las autoridades gubernamentales o administrativas dotadas de poder de decisión. El órgano no es, de esta manera, el funcionario. ${ }^{13}$ Desde entonces, hay una tendencia fuerte, incluso

${ }^{13}$ En cuanto elemento subjetivo, el funcionario (persona natural que cumple funciones públicas), no constituye una configuración suficiente del órgano, sin el concurso de un campo preciso de competencias (elemento objetivo necesario). Así, categóricamente, Crisafulli, V., "Alcune considerazioni sulla teorie degli organi dello Stato”, en Archivio giuridico N $\mathrm{N}^{\circ}$ 120, 1938, p. 79, esp. p. 90; Crosetti, A., "Organi”, en Digesto delle discipline pubblicistiche, UTET, Turín, $4^{\mathrm{a}}$ ed., 1995, p. 461. Esta es por lo demás una de las fuentes de las críticas contemporáneas dirigidas contra la noción de órgano: finalmente, entre el hombre -único capaz de expresar una voluntad-y la persona jurídica se interpone una abstracción, el órgano, quien se supone ha de emitir la voluntad de la persona jurídica. Así, Cassese, S., Le basi del diritto amministrativo, Garzanti, Milán, $3^{a}$ ed., 1995, p. 157; Claudio Franchini, "L’organizzazione", in Cassese, S., Tratato di diritto amministrativo, Giuffrè, Milán, 2000, t. I, p. 238. La cuestión es, desde los inicios, objeto de ásperos debates doctrinales; $c f$. p. ej. Esposito, C., "Organo, ufficio e soggettività dell'ufficio", Annali dell'Università di Camerino, 1932, p. 249 s., repr. en Esposito, C., Scritti giuridici scelti, II, Teoria generale dello Stato e Diritto costituzionale prerepubblicano, Jovene, Nápoles, 1999. 
mayoritaria, que ve un órgano sólo en la autoridad dotada de poder de decisión. Es así como resulta de la doctrina fundadora, aquella que Michoud ${ }^{14}$ o de Carré de Malberg ${ }^{15}$ recogieron y popularizaron en el derecho francés. En forma aún más reciente, Pierre Sabourin proponía incluso abandonar la noción de órgano, prefiriendo substituirla por aquella de "representante legal" para definir a la autoridad administrativa en derecho francés... ${ }^{16}$ lo que equivale a reconocer que sólo las autoridades investidas de cierto poder de representación habrían podido ser consideradas como órganos.

De manera más clara, es esta noción la que subyace a la argumentación de Renato Alessi en la doctrina italiana, tal vez el principal defensor de la incidencia de esta teoría en materia de responsabilidad. El autor llega incluso a evocar la idea de una relación de rappresentanza organica entre el funcionario y la colectividad pública. ${ }^{17}$

9. Se comprende sin sorpresas el riesgo oculto tras esta argumentación. Aquellos que no cumplen verdaderas funzioni sino sólo mansioni (misiones, o incluso más concretamente, tareas), se limitan a desarrollar actividades materiales, escapando así a la categoría de órganos. Se trataría de "personas naturales dependientes pero no de funcionarios de la entidad". ${ }^{18}$ Por consiguiente, la responsabilidad que a su respecto pueda incumbir al Estado o a las personas públicas de que se trate no sería una responsabilidad directa, sino indirecta, sometida en consecuencia al mecanismo ordinario de la responsabilidad civil por hecho ajeno. La traza de estas consideraciones es aún percep-

${ }^{14}$ Michoud no podía admitir que todos los funcionarios fuesen órganos, pues "los órganos del Estado son solamente los agentes o consejos que tienen un poder de decisión". La théorie de la personnalité morale et son application au droit français, LGDJ, París, $2^{a}$ ed. por L. Trotabas, 1924, § 189, t. II, p. 43 s.

${ }^{15}$ Esta restricción de la noción vaga de órgano frente a los funcionarios es manifiesta en este autor, quien invoca también las nociones de Duguit (su distinción entre gobernantes y agentes), Jèze, Michoud y Hauriou (su distinción entre "órganos administrativos" y "simples funcionarios"). Contribution, op. cit., $\S 402$, t. II, p. 390 s. Para Carré de Malberg la distinción es aún más radical, en realidad. Todo aquel que cumple órdenes, es decir, quien las ejecuta, no goza del certificado de “órgano”. Su teoría particular se inspira probablemente en Georg Jellinek, quien distinguía entre órgano mediato e inmediato, así como de las tradiciones constitucionales francesas (la diferenciación revolucionaria entre representantes y funcionarios; ibid., § 364, p. 263 s.). Es así como este autor reserva el sustantivo órgano sólo para las autoridades del Estado que expresan una voluntad inicial; los funcionarios, agentes de una voluntad subalterna, no podrían gozar del estatuto de órganos. De ahí, el autor se deja naturalmente conducir "a excluir de la lista de órganos las autoridades de cualquier suerte que ejerzan la potestad administrativa” (ibid., § 404, p. 395). La única vacilación de este autor en esta materia (ibid., § 404, p. 395, nota 10) se produce cuando se decide a refutar el pensamiento de Hauriou; como éste había rehusado atribuir a los agentes administrativos la calificación de dependientes (préposés), Carré de Malberg precisa que no pueden confundirse las autoridades administrativas "representativas" con el resto. Aquéllas "son órganos en el sentido que, dentro de los límites de sus funciones, no actúan como personas distintas del Estado"; ahora bien, "no lo son en el sentido que deban proporcionar al Estado su voluntad primera e inicial".

${ }^{16}$ Sabourin, P., Recherches sur la notion d'autorité administrative en droit français, LGDJ (col. Bibliothèque de droit public), París, 1966, p. 214 s.

${ }^{17}$ La responsabilità della pubblica amministrazione, Giuffrè, Milán, 1939, p. 153.

${ }^{18}$ Ibid., p. 160. 
tible en la doctrina italiana contemporánea, que distingue entre titulares de un oficio y adetti (agregados, o más generalmente dependientes). ${ }^{19}$

Según informa Pierre Wigny, una concepción por completo análoga a esta prevalecía en el derecho belga, al menos hasta los años sesenta. ${ }^{20}$

10. Como puede verse, la teoría del órgano no excluye la posibilidad de una responsabilidad por hecho ajeno conforme al derecho civil, al menos en forma parcial. Es, en todo caso, necesario formular una prevención: en toda administración son más los funcionarios rasos, sin poderes de decisión, que aquellos que los detentan; de este modo, el recurso parcial al derecho civil aparece como cualquier cosa menos residual.

11. Esta concepción de la teoría del órgano como presupuesto de la responsabilidad directa no es un mecanismo exclusivo del derecho público. Una parte del derecho privado intenta justificar la responsabilidad directa de las personas jurídicas privadas a base de la teoría del órgano. Basta, en efecto, con distinguir en el seno de una persona jurídica, o más generalmente de una empresa, entre aquellos entes que gozan de poder de dirección y los engranajes de simple ejecución. Órganos, los primeros, comprometen la responsabilidad de la persona jurídica en forma directa; los segundos, simples agentes, sólo pueden comprometer la responsabilidad de la empresa conforme a mecanismos de la responsabilidad por hecho ajeno.

Naturalmente, una parte de la doctrina se sintió en desacuerdo con estas ideas.

\section{b. Tentativas de extensión de la noción de órgano}

12. Maurice Hauriou pensó en algún momento que la misma teoría del órgano permitía esquivar esa alternativa entre responsabilidad directa y responsabilidad por hecho ajeno. No se olvide que el derecho francés de la responsabilidad pública puede ser presentado como la búsqueda de soluciones en rechazo al "anti-modelo" que representaba el derecho civil de la responsabilidad. ${ }^{21}$

Es difícil imaginarse cómo podría salvarse, desde la teoría del órgano, este escollo de la responsabilidad por hecho ajeno. En derecho público, la teoría del órgano permitía justamente identificar dentro de los cuadros de un servicio público a las autoridades dotadas de poder de decisión. Si un barrendero municipal pudiese concluir válidamente un contrato que ligue a la municipalidad con una empresa cualquiera de aseo, se pensaría a priori que algo anda mal, a menos que el barrendero tenga poder para representar a la comuna. Igualmente, el jefe de gabinete de un ministro, aunque le maneje la agenda

${ }^{19}$ Giannini, M. S., Diritto amministrativo, Giuffrè, Milán, 3ª ed., 1993, p. 270 s. El autor precisa que la relación de immedesimazione organica sólo vale para el titular del oficio, no para el addetto.

${ }^{20}$ Aunque el autor se mostraba crítico en aceptarla: Droit administratif. Principes généraux, Bruylant, Bruselas, $4^{\mathrm{a}}$ ed., 1962, p. 296 s.

${ }^{21}$ Así, Paillet, M., "Existe-t-il une responsabilité de droit commun?", en AAVV, Vers de nouvelles normes en droit de la responsabilité publique?, Actas del coloquio de 11 y 12 de mayo de 2001, Sénat, París, 2003 , p. 89 s. 
no puede, salvo habilitación legal, firmar por él un decreto. La teoría del órgano, en materia de actividad jurídica administrativa, designa precisamente a las autoridades dotadas de poder de decisión. De ellas se distinguen los simples agentes (engranajes anónimos del servicio). Hasta aquí, muy poca diferencia hay con el esquema general del derecho civil.

13. Hauriou pensaba sin embargo que, para efectos de la responsabilidad, todos los agentes públicos podían considerarse órganos. Así, todos los agentes públicos comprometen la responsabilidad administrativa (aunque Hauriou agregaba "mientras se mantengan en la línea de la función”). Con ello, el espectro de la responsabilidad por hecho ajeno se disipaba sustancialmente, y la responsabilidad administrativa podía decirse directa.

A decir verdad, esta es sólo una de las posiciones que sostuvo Hauriou, ${ }^{22}$ quien no negaba valor a la distinción entre órganos y agentes en el plano de la decisión ejecutoria, es decir, en el terreno del acto administrativo. ${ }^{23}$ Hauriou presiente que en la noción de órgano del Estado hay una clave importante de la responsabilidad pública por culpa, y a partir de 1911 las ediciones sucesivas de su Précis registrarán evoluciones más o menos significativas en torno a este punto, llegando al extremo de fundar sobre esta teoría, en 1919, una verdadera responsabilidad por hecho de las cosas. ${ }^{24}$ Lo cierto es que en la edición póstuma de su manual, elaborada por su hijo André y reeditada hace poco, el autor reafirma la idea de que todos los funcionarios son órganos a efectos de la responsabilidad y no hay por consiguiente motivos para distinguir entre ellos. ${ }^{25}$ Se funda no sólo en la idea de que si el agente no sale de su función continua siendo "un órgano identificado con la persona jurídica, sino [en que] la personalidad de este agente desaparece en el órgano colectivo que constituye 'el servicio"”. 26 "En materia de responsabilidad por culpa el órgano susceptible de comprometer a la administración es el servicio público entendido como organismo complejo". ${ }^{27}$

${ }^{22}$ Vinculada a la responsabilidad por culpa, la noción de órgano aparece recién en la séptima edición del Précis de droit administratif et de droit public (Sirey, París, $7^{\mathrm{a}}$ ed., 1911, p. 491 s.). La sexta edición no hace ninguna referencia a la materia; al contrario, hasta entonces el autor afirmaba la existencia de "simples dependientes o simples funcionarios [que] no son elementos de la personalidad administrativa, sino dependientes de ella" (Sirey, París, 6a ed., 1907, p. 62). La expresión retenida por Hauriou en la cita corresponde literalmente a préposé, misma noción que identifica al dependiente en la responsabilidad civil por hecho ajeno.

23 Para no salir de la $7^{\mathrm{a}}$ ed., v. p. 115.

${ }^{24}$ Siendo el órgano una propiedad de la administración del mismo tipo que las cosas, "la responsabilidad de la administración por hecho de servicio es, pues, en realidad, una responsabilidad por hecho de la cosa que se tiene bajo guarda (art. 1384 del Código Civil), y la culpa de la administración consiste en haber vigilado mal su cosa”. Précis de droit administratif et de droit public, Sirey, París, 9a ed., 1919, p. 530.

${ }^{25}$ Précis de droit administratif et de droit public, Sirey, París, 12 ed., por A. Hauriou, 1933 (reimpresión Dalloz, París, 2002).

${ }^{26}$ Précis de droit administratif et de droit public, $7^{\mathrm{a}}$ ed., 1911, op. cit., p. 493.

${ }^{27}$ Précis de droit administratif et de droit public, $12^{\mathrm{a}}$ ed., 1933, op. cit., p. 517. 
14. Aparentemente, este es el sentido que recogió Hugo Caldera en su exposición (aunque sin decirlo). Para llegar a esta conclusión, que atribuye a todo funcionario carácter de órgano, es necesario mudar la relación de imputación. El pasaje de una imputación a otra es casi insensible en la doctrina de Caldera; sin embargo, la validez de su postulado no puede verificarse científicamente. Caldera comenzaba tratando de mostrar cómo, por medio de la teoría del órgano, "los actos de la administración son imputables u oponibles directamente al Estado"; en cambio, concluía señalando una imputación de daños: "La teoría del órgano se limita a constatar, para imputar un perjuicio al Estado, si el daño ha sido causado como consecuencia de la actuación" de un agente público. ${ }^{28}$ Aunque el vocabulario era idéntico, el registro es completamente diverso: imputar un daño a alguien ¿acaso no es determinar que él debe soportarlo? El salto lógico es manifiesto.

En realidad Caldera define el órgano en función de la responsabilidad. En ello parece seguir al último Hauriou, quien en realidad sólo trataba de interpretar conceptualmente el derecho positivo, vale decir, las soluciones jurisprudenciales. Es la generalización de la responsabilidad por faltas de servicio cometidas por los agentes públicos lo que mueve a Hauriou a postular la generalización de la noción de órgano. Pero con humildad, el autor reconocía que el juez había llegado a estas soluciones en forma "instintiva", ${ }^{29}$ sin nunca preocuparse del órgano sino más bien de las prosaicas necesidades de protección de los funcionarios. En cualquier caso, al atribuir a la responsabilidad naturaleza orgánica, el razonamiento es tautológico, y por consiguiente desprovisto de sentido.

15. No puede pasarse por alto una observación metodológica: la teoría del órgano deviene, mediante esta explicación, una teoría bicéfala. En cuanto sinónimo de imputación (que es su núcleo esencial), hay que distinguir pues entre actos jurídicos y responsabilidad. Pero mientras en materia de actos jurídicos la teoría conserva utilidad, pues delimita la esfera de quienes pueden comprometer al Estado o las personas públicas, en materia de responsabilidad ninguna limitación es necesaria. La teoría del órgano proporciona el marco general que atribuye a los agentes del Estado la facultad de comprometer a la persona pública, pero ella no ejerce ningún rol técnico: no es necesario determinar concretamente si tal o cual agente es o no un órgano, ya que por definición todos lo son.

Uno tiene la impresión de que con ello la teoría pierde su fuerza explicativa general, pues no excluye las particularidades (enormes) de la responsabilidad. Ninguna de las dos concepciones está, en efecto, exenta de limitaciones en cuanto a la responsabilidad.

\section{LAS LIMITACIONES DE LA TEORÍA}

16. La teoría del órgano es una teoría ficticia. Rechaza la realidad, que consiste en la intervención inevitable del hecho de un hombre en el origen del daño. Abrazar la teoría implica cerrar los ojos a la realidad, con el riesgo importante de dejar de ver algunas

\footnotetext{
${ }^{28}$ RDP-UCh N ${ }^{\circ}$ 25-26, op. cit., p. 176; Sistema, op. cit., p. 207.

${ }^{29}$ Précis de droit administratif et de droit public, Sirey, París, $8^{a}$ ed., 1914, p. 496.
} 
cosas. Mientras la concepción restrictiva del órgano descuida la manera en que se gestiona el interés público (a), la concepción extensiva deja de lado al funcionario, quien sigue siendo un ciudadano, un cives (b).

\section{a. Una teoría incapaz de aprehender el fenómeno público}

17. La noción de órgano como autoridad revestida de poder de decisión parece cada vez más inútil, como ha subrayado Forsthoff, para dar cuenta de las manifestaciones actuales de la administración en el Estado de bienestar. ${ }^{30}$ La administración actúa, en efecto, cada vez más seguido por medio de actos materiales (desde las prestaciones médicas hasta el estudio de los antecedentes de una iniciativa reglamentaria, por ejemplo), y no por medio de actos jurídicos. La definición de lo administrativo, así como de la autoridad, necesita recurrir a otros signos distintivos en la época actual.

18. Al poner el acento en el poder de decisión, la teoría restrictiva del órgano coloca al sector más importante del cuerpo de empleados públicos en una situación desventajosa. Los subalternos cometen, contrariamente a los órganos, culpas civiles ordinarias; estas culpas podrán en muchos casos comprometer la responsabilidad del servicio según el mecanismo de la responsabilidad por hecho ajeno, pero seguirán pesando eventualmente sobre sus patrimonios. Ellos están a disposición de las víctimas, expuestos a rencillas y molestias judiciales, cuando no a la venganza de los jefes que quieran repetir en su contra.

Tal vez el recurso a la teoría se justifica en el derecho privado. El dueño de la empresa, quien la ha creado como persona jurídica, busca sin duda resguardar su patrimonio personal. La teoría del órgano le suministra el útil para desaparecer detrás de la forma societaria. Los empleados, en cambio -en un esquema ajeno a la responsabilidad por riesgo- sólo pueden comprometer la responsabilidad de la firma mediante el artificio de la responsabilidad por hecho ajeno, con la eventualidad de acciones de repetición. Nada de esto está presente en el derecho público, en que por encumbrado que sea el órgano, nunca es "dueño" del aparato estatal. Aunque pueda remontarse del agente autor del daño a su jefe, y de éste a su jefe y así, sucesivamente, nunca podrá llegarse más lejos que a una autoridad comisaria del interés público. En realidad, la teoría puede manifestarse como clasista, porque el alto funcionario, el jefe del servicio es justamente el órgano cuyos actos se identifican con los del servicio. ${ }^{31}$ Mientras el ministro o el jefe

${ }^{30}$ Forsthoff, E., Traité de droit administratif allemand, Bruselas, Bruylant, trad. por M. Fromont, 1969, p. $647 \mathrm{~s}$.

31 Cf. las reflexiones del comisario de gobierno Jean Kahn en sus conclusiones sobre el arrêt Jeannier, Conseil d'Etat - Section, 22.03.1957, Recueil Lebon, 1957, p. 196, concl., Recueil Dalloz 1957, p. 748, concl., n. Weil, Juris-classeur périodique (La semaine juridique) 1957, II, N 10303 bis, n. Louis-Lucas, Actualité juridique - Droit administratif 1957, 4, p. 186, chr. Fournier y Braibant, Recueil Sirey 1958, 3, p. 2, concl. 
nunca serán molestados, para los subalternos (que es casi como decir para el "perraje”) no habría ninguna garantía patrimonial.

No obstante, no puede pensarse seriamente que los subalternos sean una nada jurídica. Es difícil defender este punto hoy día, en que la crítica contingente demoniza -desde la política, o desde la ciencia administrativa- la "grasa" que representan muchos funcionarios inútiles. Lo cierto es que ningún ministerio funciona sólo con caciques; todo servicio debe poseer algo de personal. En el imaginario común, por lo demás, "los administrativos" son precisamente esos servidores pequeños, los engranajes anónimos del aparato estatal. Todos ellos forman parte de la administración, la que opera en el hecho como un complejo. La teoría restrictiva del órgano sólo conduce a descuidar este aspecto, que es tan administrativo como el que más.

Sin embargo, el riesgo de un retorno a las reglas del derecho privado no está ausente de la concepción extensiva del órgano.

\section{b. Una teoría ciega frente a la responsabilidad privada}

19. La responsabilidad civil (privada) es un dato que el derecho administrativo no puede ignorar. Las tentativas de dotar a la responsabilidad pública de un estatuto autónomo conducen, sin embargo, a menudo a descuidar este aspecto, en circunstancias que sería más sensato preguntarse cómo dosificar mejor esta responsabilidad civil.

20. Hauriou no descartaba la responsabilidad civil, de hecho, pero la excluía del ámbito del derecho público. En la teoría de Hauriou no había lugar al cúmulo de responsabilidades. El agente es órgano en cuanto actúa en la línea de la función, pero vuelve a ser un ciudadano común y corriente cuando sale de esa línea de la función. Sus actos se imputan, pues, según las circunstancias, ya sea a su autor o al servicio, pero en caso alguno se mezclan.

La construcción de este autor basada en la teoría del órgano está enteramente dirigida a descartar el cúmulo de responsabilidades. Por cierto, su formulación alejaba el riesgo de clasismo, pues todo agente -sin distinción- que se sale de "los límites sicológicos de la función” cesa de ser órgano y no compromete más que su responsabilidad individual. ${ }^{32}$

Tal solución había sido desechada en Francia varios años antes de la edición póstuma del Précis de Hauriou. ${ }^{33}$ Éste nunca pudo aceptar la solución del arrêt Lemonnier, porque en último análisis ella implicaba atribuir a la responsabilidad del servicio el rol de regla general, en circunstancias que el dato primario era para él la culpa civil ordinaria. ${ }^{34}$

${ }^{32}$ Précis de droit administratif et de droit public, $7^{\mathrm{a}}$ ed., 1911, op. cit., p. 492.

33 CE, 26.07.1918, Époux Lemonnier, Recueil Lebon, 1918, p. 761, concl. Blum, Recueil Dalloz 1918, 3, p. 9, concl., Revue du droit public 1919, p. 41, concl., n. G. Jèze, Recueil Sirey 1918-1919, 3, p. 41, concl., n. M. Hauriou, Les grands arrêts de la jurisprudence administrative, Dalloz, París, 12a ed., 1999, N 35, p. $201 \mathrm{~s}$.

${ }^{34}$ Précis de droit administratif et de droit public, Sirey, París, $10^{\mathrm{a}}$ ed., 1921, p. 380, nota 1. Hauriou juzga inaceptable esta idea de L. Blum que la "responsabilidad del servicio es la regla y es la regla porque, 
Si el arrêt Lemonnier (o mejor: las conclusiones de Léon Blum) debiese ser explicado, la teoría del órgano se revela incapaz para hacerlo. La responsabilidad del servicio en este caso "ya no se basa en la falta de servicio, pues ello sería decir que el servicio está en culpa por existir, lo cual sería absurdo; en realidad, ella estaría basada en el riesgo; la empresa de servicio público, en sí misma, comportaría riesgos contra los cuales la administración debería asegurar al público". 35

21. En realidad la tesis de Hauriou, quien parece ser el fundador de esta vertiente extensiva de la teoría del órgano, no era incoherente. El autor se mostraba, sin embargo, demasiado apegado a la noción de órgano para ver sus limitaciones. La teoría presenta una dificultad importante de aplicación, pues si todos los agentes públicos son órganos, todos son también personas privadas y por consiguiente sujetos de la responsabilidad civil en algún caso. Puesto que el carácter orgánico no sirve para establecer distinciones entre los actos que dependen de la responsabilidad civil o de la responsabilidad pública, como en muchas materias "no es necesario tomar en serio la metáfora del órgano". 36 En cambio, es necesario recurrir a un criterio funcional de distinción, lo que es algo enteramente diverso.

22. Las limitaciones de la teoría impiden asignarle el rol de una regla de responsabilidad. La extensión de la responsabilidad pública parece no depender de estas consideraciones orgánicas. Para comprender esta extensión, al menos en Chile, es necesario recurrir a los datos del derecho positivo.

\section{B. EXTENSIÓN DE LA RESPONSABILIDAD PÚBLICA}

23. Ante todo, es preciso tener en cuenta que la teoría del órgano no encierra una regla de responsabilidad, sino simplemente una explicación posible de las reglas de imputación a las personas públicas de los actos de sus agentes. La extensión de la responsabilidad pública, en el sentido de los diferentes regímenes que puedan presentarse, no depende por consiguiente de la teoría del órgano. De ella no deriva una regla de responsabilidad que prescinda de toda connotación culposa (I) ni, en el plano general, una que deslinde de manera confiable los ámbitos de responsabilidad pública y privada (II).

incluso en las hipótesis en que el agente ha cometido un hecho personal, es el servicio quien ha puesto a la víctima en contacto con el agente culpable, lo que significa decir que el servicio sería responsable de todos los actos cometidos por el agente en ejercicio de sus funciones, incluso cuando estos serían hechos personales que se separan de la función".

35 Ibid.

${ }^{36}$ Galgano, F., Delle persone giuridiche, in Scialoja, A. y Branca, G., Commentario del Codice civile, Zanichelli-Foro Italiano, Bolonia-Roma, 1969, p. 64. 


\section{Neutralidad de la teoría del órgano frente a la responsabilidad "objetiva"}

24. Puesto que la teoría del órgano no encierra reglas de responsabilidad parecería inapropiado extraer de ella una regla de responsabilidad objetiva o sin culpa. Sobre este particular, la afirmación que Hugo Caldera formulara hace años, en el sentido que la teoría del órgano permite fundar el carácter objetivo que poseería casi por naturaleza la responsabilidad pública, no pasa de ser una afirmación, a pesar de la recepción de estas ideas por parte de la jurisprudencia. ${ }^{37}$

25. Desde luego, no encierra una regla de responsabilidad tratándose de los "actos lícitos”, como suele decirse en el medio nacional. Como esos actos lícitos son por lo general actos administrativos regulares, la teoría del órgano sólo puede ser de alguna ayuda en la identificación de esos actos. En efecto, si quien los adopta es un órgano, es posible que esos actos sean regulares; en caso contrario, hay un indicio fuerte de su ilegalidad (al menos por incompetencia). Pero nada de eso dice bajo qué condiciones han de repararse las consecuencias de esos actos. El recurso a otras reglas, que sean efectivamente reglas de responsabilidad, se torna ineludible.

26. Caldera pudo referirse quizá al comentario clásico de Charles Eisenmann. Para este autor, como las personas públicas carecen de existencia real no pueden cometer culpa; así, "aquello que se da como responsabilidad por culpa es en realidad una responsabilidad sin culpa... del responsable”. ${ }^{38}$

Atribuir a Caldera esta interpretación resulta extravagante, y no sólo por el repudio nada tímido de Eisenmann a las teorías organicistas, ${ }^{39}$ sino porque la teoría del órgano busca justamente metamorfosear la realidad para atribuir culpas a las personas jurídicas.

La teoría se muestra, en efecto, idónea para explicar la mecánica de una responsabilidad por culpa de cuño clásico. En la medida que la teoría del órgano fue imaginada para sustituir a la relación de representación aceptada hasta el siglo XIX como mecanismo de imputación (mandato), ella podría conducir a resultados diametralmente opuestos a los perseguidos por Caldera. La imputación que apareja la teoría del órgano es tan intensa que recubre estados

${ }^{37}$ Así, p. ej., CA Santiago, 27.12.1993, c/ SAG (cons. 2), GJ No 162, 1993, p. 58; 08.11.1994, Rodríguez Guaita cl SAG, (cons. 2 impl.), GJ No 173, 1994, p. 95; 1 JLCiv Temuco, 24.06.1999, Méndez Fernández cl Fisco (cons. 12), conf. CA Temuco, 11.04.2001, CS, 06.06.2001, LN N 18808; JL Arauco, 21.06.2001, Sociedad Ingeniería y Construcción Socoin Limitada c/ M. Arauco (cons. 29), conf. CA Concepción, 08.10.2003, CS, 25.10.2004, LN N 31333; CA San Miguel, 29.08.2003, cl Concha Orellana (cons. 26) conf. CS, 03.05.2004, LN N ${ }^{\circ}$ 30166. Para otra formulación, cf. la decisión inédita del 18 JLCiv Santiago, 22.10.1999, Vargas Vargas c/ Fisco (cons. 13), rol N 4397-1997, de la que parecen calcadas las del 7 JLCiv. Santiago, 31.05.2004, Flores Gálvez cl Fisco (cons. 11), rol No 4584-2002; 08.06.2004, Tognola Canales cl Fisco (cons. 9), rol No 3784-2002; y 29.07.2004, Parada Muñoz c/Fisco (cons. 14), rol N 2587-2003.

38 "Sur le degré d’originalité du régime de la responsabilité extra-contractuelle des personnes (collectivités) publiques”, en Juris-classeur périodique (La semaine juridique) 1949, I, No 751, §8.

${ }^{39}$ Ibíd., $\$ 17$ (refiriéndose a la mitología de la "falta del servicio público"). Cf. también sus desarrollos sobre la materia en Cours de droit administratif, Paris, LGDJ, 1983, t. II, p. 835. 
subjetivos del agente que detenta la calidad de órgano. La doctrina italiana ha llevado estos desarrollos hasta el extremo de suponer mediante la idea de una relación de immedesimazione ${ }^{40}$ entre el órgano y el Estado, que el acto del órgano ya no se asimila a un acto del Estado. Está tan anclado en el Estado que cuando el órgano actúa, es el Estado mismo quien actúa. De este modo, la teoría del órgano permite imputar a la administración de que se trate "los estados mentales e intencionales, como el error de hecho o la representación personal de los fines, los estados de conciencia tales como la buena fe, las calificaciones de conducta de los agentes, como la negligencia o la malicia”. ${ }^{41}$ Puede pensarse, pues, que en materia contractual la teoría del órgano permitiría, por ejemplo, extender al Estado el tratamiento legal de los vicios del consentimiento. Entonces, ¿por qué no admitir que esta teoría conduce a una responsabilidad "subjetiva”, conforme a los modelos más rancios - incluso añejos - de la responsabilidad civil? Si el acto del órgano es el acto del Estado, entonces la responsabilidad de éste podría estar sujeta a la exigencia de una culpa, incluso del dolo, según las enseñanzas clásicas (felizmente superadas) de la doctrina civil del siglo XIX. Del mismo modo que en derecho privado, con esta teoría no podría encontrarse "ningún obstáculo de orden lógico abstracto" a las imputaciones de este género. ${ }^{42}$

Sin embargo, la teoría - hay que repetirlo - encierra simplemente una interpretación figurativa acerca de las reglas de imputación del acto de una persona física a una persona jurídica. No comprende reglas de responsabilidad. Es por esta neutralidad de la teoría del órgano en cuanto al régimen de responsabilidad aplicable, que su única utilidad podría residir (es lo que hay que verificar) en la delimitación de las esferas de la responsabilidad pública y de la responsabilidad privada, cuestión que se halla en el corazón del régimen general de responsabilidad.

\section{La teoría del órgano y el carácter directo o indirecto de la responsabilidad pública}

27. Para la Ley, la responsabilidad del Estado no tiene por naturaleza carácter directo. El art. 4 de la Ley de Bases provee un cuadro general en que pueden coexistir una responsabilidad directa y una responsabilidad indirecta. Esta regla, como es bien sabido, dispone que "el Estado será responsable por los daños que causen los órganos de la Administración en el ejercicio de sus funciones, sin perjuicio de las responsabilidades que pudieren afectar al funcionario que los hubiere ocasionado".

La posibilidad de extraer de esta norma una regla de responsabilidad directa debe contrastarse con la parte final del enunciado: "sin perjuicio de las responsabilidades

${ }^{40}$ Cf. Crisafulli, V., op. cit., p. 83 s.

${ }^{41}$ Giannini, M. S., Diritto amministrativo, op. cit. p. 147 s. Esta imputación, recalca el autor, opera de "modo que la administración no sólo recibe la imputación de los actos válidos, sino también de los inválidos, de las conductas negligentes, maliciosas y dolosas del titular del oficio hasta el límite del dolo penal" (ibíd., p. 272). Después de la imputación propia de las personas naturales, dice Giannini en otra parte ("Organi [teoria generale]”, Enciclopedia del diritto, t. 31, Giuffrè, Milán, 1981, p. 37 s.), aquella del órgano es "la más amplia de las imputaciones jurídicas" que puedan concebirse (p. 46).

42 Galgano, F., op. cit., p. 65. 
que pudieren afectar al funcionario que los hubiere ocasionado". La ley reconoce, pues, que el Estado responde pero que tras esa responsabilidad puede también subsistir una responsabilidad personal del agente. En otros términos, la ley reconoce que, si el Estado responde, en ocasiones responde por el agente.

28. Sólo en dos casos la responsabilidad podría decirse directa: si la eventualidad de una culpa del funcionario carece de incidencia para comprometer la responsabilidad o si tal culpa no genera ninguna consecuencia para su autor material; en ambas hipótesis, ninguna responsabilidad personal incumbe al agente. El primer caso se presenta en ausencia de responsabilidad del agente (hipótesis cubiertas, grosso modo, por una responsabilidad "objetiva” o sin culpa). El segundo, en el evento previsto en el art. 42 de la ley: la falta de servicio (porque aquí la acción de repetición está implícitamente descartada por la ley). No interesa aquí verificar si efectivamente el art. 4 consagra una regla de responsabilidad objetiva; puede admitírselo como una hipótesis de trabajo (por lo demás, estas responsabilidades sin culpa existen en la jurisprudencia y sería ingenuo negarlo).

29. Interesa retener del art. 4 su vocación amplia para recoger estas dos clases de responsabilidad: directa e indirecta. La concepción de la administración que subyace a esta regla debiera ser suficientemente amplia para justificar que el Estado responda por hechos suyos y por hechos ajenos. La teoría del órgano, cuya vocación es atribuir a la persona jurídica actos propios o personales a ella no parece susceptible de explicar la riqueza del derecho positivo. A lo más, ejerce una influencia parcial y limitada, sin excluir la incidencia de otras nociones. De este modo, la teoría del órgano se muestra incapaz para explicar la extensión de la responsabilidad del Estado en el derecho positivo. Tanto la responsabilidad directa (a) como la responsabilidad indirecta (b) son indiferentes a la teoría del órgano.

a. El carácter directo de la responsabilidad pública no depende de la teoría del órgano

30. Ante todo, no puede negarse que en Chile la doctrina y (episódicamente) la jurisprudencia creen ver en el carácter "orgánico" de la responsabilidad una de las razones que justifican su carácter directo. La jurisprudencia recurre con alguna frecuencia a este adjetivo "directo", aunque parece dudar sobre el lugar donde pegarlo, es decir, sobre la cosa que él califica: a veces habla de una imputación directa de los actos de la administración, ${ }^{43}$ a veces de la responsabilidad misma, ${ }^{44}$ pero también del

${ }^{43}$ Así, el fallo CA Concepción, 31.03.1999, Aja García y otros c/ M. Concepción (cons. 1), RDJ No 96, 1999, II, 5a , p. 59. O las decisiones precitadas del 18 JLCiv Santiago, 22.10.1999, Vargas Vargas c/ Fisco, (cons. 12), y del 7 JLCiv. Santiago: 31.05.2004, Flores Gálvez cl Fisco (cons. 10), 08.06.2004, Tognola Canales c/ Fisco (cons. 8), 29.07.2004, Parada Muñoz c/Fisco (cons. 13).

${ }^{44}$ CA Valparaíso, 15.04.2002, cl SS Viña del Mar-Quillota, LN N 24512 (cons. 1); 10.08.2000, CA Concepción, Oviedo Pérez cl SS Talcabuano (cons. 15), GJ No 259, 2002, p. 38, conf. CS, 24.01.2002, FM No 497, 2000-2002, p. 370. 
perjuicio. ${ }^{45}$ En filigrana, esas calificaciones se reconducen a la conclusión según la cual el hecho del órgano importaría siempre, cumpliendo las condiciones normales, la responsabilidad por hecho propio del Estado. Estas afirmaciones jurisprudenciales se fundan seguramente en la doctrina de Hugo Caldera. Haciendo abstracción de la confusión metodológica y conceptual de esa doctrina, fácilmente extraíble de lo expuesto precedentemente, conviene preguntarse si la responsabilidad directa que derivaría de la Ley de Bases traduce concepciones propias de la teoría del órgano, o en otros términos, debe analizarse si esta responsabilidad directa deriva del carácter de órgano del agente dañoso.

31. Un buen argumento a favor de esta tesis es el empleo por los arts. 4 y 42 de la voz "órgano".

Un análisis más profundo conduce a concluir sin embargo que la ley no excluyó consideraciones de naturaleza funcional (i) que relativizan la importancia del órgano. Este criterio funcional adquiere relevancia práctica en la distinción entre falta personal y falta de servicio (ii).

\section{(i) La relevancia de los criterios funcionales}

32. Se ha visto que la ley no utilizó un concepto muy técnico del órgano. El art. 4 suministra una prueba suplementaria de ello (si fuera necesaria una más): el daño aparece aquí causado tanto por el órgano como por el funcionario. Podría suponerse que el órgano es asimilado por este artículo al funcionario, y como no hay mayores restricciones legales, cabría sostener al modo de Hauriou que todo funcionario es órgano, es decir, que la tesis extensiva fue recogida por la ley.

33. La conclusión que deriva de esta interpretación consiste, paradójicamente, en la irrelevancia de la teoría. Si todo funcionario tiene calidad de órgano, finalmente importa poco el elemento orgánico: basta que el daño sea cometido por un funcionario.

La jurisprudencia va en este sentido cuando decide pasar por alto las condiciones estatutarias que rigen las relaciones entre un servicio público y su personal. Esta tendencia se ha fortalecido desde el caso Ortega Weason, en que la jurisprudencia decidió, aunque desde el derecho privado, hacer responsable a un servicio de salud por los daños provocados por un alumno en práctica en un hospital. ${ }^{46}$ El fallo Béraud debía reafirmarlo

45 Sin explicar, por cierto, qué es una imputación (directa) "del daño" a la administración, fallos precitados: CA Santiago, 27.12.1993, cl SAG (cons. 2); 08.11.1994, Rodríguez Guaita cl SAG (cons. 2 impl.); 1 JLCiv Temuco, 24.06.1999, Méndez Fernández c/ Fisco (cons. 12); JL Arauco, 21.06.2001, Sociedad Ingeniería y Construcción Socoin Limitada cl M. Arauco (cons. 29); CA San Miguel, 29.08.2003, cl Concha Orellana (cons. 26).

${ }^{46}$ CA Santiago, 23.08.1983, cl Ortega Weason, conf. CS, 04.10 .1984 (cons. 10-d, e, f), RDJ No 81, 1984, II, 4a , p. 206, GJ N 55 , 1985, p. 2 n. Soto K., FM N 311,1984 , p. 559, repr. in Soto K., E., Derecho administrativo. Bases generales, II, El principio de juridicidad, Jurídica, Santiago, 1996, p. 355 s. e in Vásquez, A., Responsabilidad del Estado por sus servicios de salud, Conosur, Santiago, 1999, p. 131 s. La hipótesis (in- 
aún más, mediante la declaración de que la responsabilidad del Estado no se ve alterada por "la naturaleza del vínculo laboral o régimen que gobierna las relaciones laborales de ese personal" con el ente público, incluso si se trata de meros agentes contractuales. ${ }^{47}$ Con esa afirmación la jurisprudencia pareció alejarse de una concepción orgánica de la administración, a pesar, curiosamente, de reconocer la aplicabilidad de la teoría. Lo que resulta de este pronunciamiento es que, más que ser un órgano, el agente del daño debía cumplir funciones públicas. El estado de cosas generado por esa decisión, antigua pero nunca desmentida, puede parecer mucho más cercano a la idea de "masa homogénea" de funcionarios que evocaba René Chapus en su tesis doctoral. ${ }^{48}$

34. De este modo, cualquier agente que asuma funciones administrativas podría comprometer la responsabilidad pública. Inversamente, el funcionario no compromete la responsabilidad pública si no ha actuado en ejercicio de sus funciones, y este punto complica aún más la suerte de la teoría. Descartada la tesis restrictiva del órgano, la tesis extensiva tampoco parece recogida por la ley, al menos en la versión de Hauriou. Porque para Hauriou el agente era órgano sólo en cuanto se mantuviera en la línea de la función, dejaba de serlo desde que salía de esos límites. El art. 4 de la Ley de Bases reconoce literalmente, en cambio, que un órgano puede actuar fuera del ejercicio de sus funciones, lo cual equivale casi a reconocer que alguien puede ser órgano y no serlo a la vez, funcionario y sujeto privado al mismo tiempo.

La ley no desconoció, en suma, que el funcionario sigue siendo un ciudadano. La calidad de órgano que reviste no permite deslindar las responsabilidades que sus actos generan. Por eso, lo que interesa a la ley es el ejercicio de las funciones públicas por parte de un funcionario. Para determinar la aplicación del derecho público de la responsabilidad, su criterio principal es funcional, más que orgánico.

35. La cuestión del carácter orgánico de la responsabilidad podría plantearse en otros supuestos más complejos, como el planteado por el profesor Viñuela ${ }^{49}$ para extender al Estado la responsabilidad en que pueda incurrir un concesionario de obras públicas. El agente del daño no es, en tal caso, un órgano del Estado en sentido clásico: no forma parte de los cuadros de la administración. Podría ser interesante explorar vías para

tervención de alumnos no titulados en actividades hospitalarias públicas) fue implícitamente legitimada también por el fallo CS, 02.07.1998, cl Garrido Castillo y otro, RDJ Nº 95, 1998, II, 4ª, p. 95, GJ N² 217 , 1998 , p. 113.

47 Sentencia de primera instancia, 28.03.1995, Béraud c/ Fisco (cons. 73), conf. CA Santiago, 21.09.1995, cit. por López, J., "Responsabilidad por falta de servicio. Casuística chilena reciente”, RDJ No 94, 1997, I, p. 31 (esp., p. 36 s.), conf. CS, 20.07.1996, FM N 451, 1996, p. 1228.

${ }^{48}$ Responsabilité publique et responsabilité privée. Les influences réciproques des jurisprudences administrative et judiciaire, LGDJ (col. Bibliothèque de droit public), París, 1954, § 205.

49 Viñuela, M., "La responsabilidad por falta de servicio en el contexto del régimen de concesiones viales vigente en Chile", en IusP N 7, 2001, p. 35 (p. 41), "La concesión de obras públicas en Chile: ¿Privatización de la responsabilidad del Estado en la empresa concesionaria?”, en Responsabilidad civil de entidades corporativas, Cuadernos de extensión jurídica - U. de Los Andes (2003) 7.109 (p. 122). 
atribuir al concesionario la condición de órgano del Estado. Si satisface misiones de interés general en forma regular y continua podría sostenerse que se trata de un servicio público. Asimilando el servicio al órgano, como hacía Hauriou y parece hacer la Ley de Bases, el concesionario podría ser considerado un órgano del Estado. Pero aquí la teoría del órgano debería necesariamente revestirse de una concepción material de lo administrativo: es manifiesto que ella no operaría en forma autónoma.

De todas formas, aunque pudiera parecer aceptable que el concesionario sea un órgano del Estado, no es seguro que sea el Estado quien deba responder por sus hechos. El Estado de que habla el art. 4 ¿es el Estado-Fisco? Se sabe que hay diversas acepciones de la voz "Estado", y la más general de ellas abarca (entre otros) a todas las entidades públicas, personificadas o no, que cumplen funciones administrativas. ${ }^{50} \mathrm{Si}$ el art. $4 \mathrm{de}$ la Ley de Bases se aplica a los servicios de salud, por ejemplo, no es el patrimonio fiscal quien responde, sino el propio servicio de salud, quien sigue sin embargo siendo, lato sensu, parte del Estado. ${ }^{51}$ Atribuir a un concesionario el carácter de órgano administrativo podría normalmente dar pie a extenderle, en cuanto cumpla misiones de servicio público, el régimen administrativo de la responsabilidad ${ }^{52}$, pero es discutible que corresponda hacerle beneficiar de la garantía del Fisco.

Distinto sería el caso de un agente privado que cumple funciones públicas por cuenta de una persona pública, en que habría buenas razones para desear construir un vínculo de imputación más sólido a su respecto. Pero no es ese el caso planteado por Viñuela.

Estas hipótesis, que sería interesante ver recogidas por la jurisprudencia, no reposan en todo caso sobre una concepción orgánica de la administración, sino sobre una concepción funcional. Es también, como se ha visto, ese criterio funcional el que permite diferenciar los ámbitos de las responsabilidades directa e indirecta de las personas públicas.

\section{(ii) Responsabilidad directa, falta de servicio y falta personal}

36. Hasta aquí nada indica bajo qué condiciones la responsabilidad puede ser directa o por hecho propio del Estado. El art. 4 sólo describe el cuadro general para que el Estado concurra a la reparación de un daño. En otros términos, con la simple lectura del art. 4 nunca puede estarse seguro de que el Estado pague por entuertos propios.

${ }^{50}$ Cf. CS, 19.11.2003, Municipalidad de Cauquenes cl Fisco, Rol N 3075-2002.

${ }^{51}$ Cf. CA La Serena, 22.11.1989, Morales Aguirre c/ SS Coquimbo, LN N ${ }^{\circ}$ 10929, repr. in Vásquez, A., op. cit., p. 209 s. El fallo rehusó aplicar al proceso seguido contra un servicio de salud las reglas del juicio de hacienda, pues no era el interés fiscal el concernido.

52 Pero la jurisprudencia ha eludido esta cuestión: implícitamente (y tratándose de otra clase de “concesionarios”), JL Villarrica, 23.11.2001, Compañía de Seguros Generales Aetna Chile S.A. c/ M. Villarrica y Empresa de Servicios Sanitarios de La Araucanía S. A., conf. CA Temuco, 20.01.2004, CS, 29.09.2004, LN $\mathrm{N}^{\circ} 30939$. 
37. Si podía pensarse que la Ley recogía la tesis de Hauriou, debe recordarse que para éste el campo natural de la responsabilidad pública era la falta de servicio (o hecho de servicio, en su lenguaje aún arcaico), aspecto que reafirmaba al señalar que el órgano de que se trata era el servicio público.

Es entonces en el art. 42 de la Ley de Bases que deben buscarse pistas más útiles en torno al carácter directo de la responsabilidad. El texto de esta regla es conocido. Dice que "los órganos de la Administración serán responsables del daño que causen por falta de servicio. "No obstante, el Estado tendrá derecho a repetir en contra del funcionario que hubiere incurrido en falta personal". Este precepto alude a dos conceptos surgidos de la tradición francesa: falta de servicio y falta personal. La articulación de estas dos nociones puede dejar ver la existencia de una responsabilidad directa, mediante una interpretación a contrario: como la falta personal habilita a la administración a retornarse contra el funcionario, sólo cabría hablar de responsabilidad directa cuando el Estado responda por un hecho que no constituya una falta personal. El art. 42 deja en claro que el Estado puede ver comprometida su responsabilidad en estos dos supuestos (respecto de la falta personal, precisamente porque ella da pábulo al ejercicio de acciones de repetición). No obstante, este precepto no indica de qué forma pueden coexistir estas dos nociones en una misma hipótesis: sólo da a entender que no son excluyentes entre sí.

Una lectura conforme a la esquematización francesa permitiría imaginar combinaciones posibles de estos conceptos, en especial su coexistencia parcial en un mismo hecho (falta de servicio acumulada o provocada por una falta personal o viceversa), o incluso su identificación accidental (falta de servicio que constituye, además, una falta personal). En estos dos casos, también cabría lugar a una responsabilidad directa, aunque confundida con una responsabilidad indirecta en proporciones variables. ${ }^{53}$

Esta presentación de la responsabilidad directa no exige a priori una definición precisa de las nociones de falta de servicio y la falta personal, de modo que parecería susceptible de adaptarse a otras nociones que desconozcan la tradición francesa (y su recepción por la Ley de Bases). Para poder deducir del art. 42 una responsabilidad directa sólo es preciso que falta de servicio y falta personal sean conceptos distintos entre sí. ${ }^{54}$

53 Por cierto, caben lecturas distintas, que anulan toda posibilidad de dar carácter directo a la responsabilidad. Imagínese p. ej. que estos conceptos carecen de densidad conceptual y que son etiquetas removibles: cuando el Estado responde el juez emplea la expresión falta de servicio; pero podría calificar el mismo hecho como falta personal (aunque el juez usará probablemente su nombre más conocido, la expresión culpa civil) si la acción se dirige -incluso por el mismo Estado-contra el funcionario. Esta solución debe ser descartada, prefiriéndole otra que asigne un significado sustancial a las nociones de falta de servicio y falta personal: si el Estado pudiese siempre retornarse contra el funcionario, en realidad no cargaría nunca con el peso de la reparación y no podría seriamente hablarse de responsabilidad a su respecto.

${ }^{54}$ No obstante, parece más fructífero definir falta de servicio y falta personal mediante sus antecedentes franceses (que constituyen su raíz histórica) que por medio de otras ideas. En especial, la definición de falta de servicio como omisión de servicio (v. p. ej., Soto K., E., nota sobre el fallo CA Concepción, 18.12.2003, Torres Velásquez c/ SS Talcabuano, en IusP N $\mathrm{N}^{\circ}$ 12, 2004, p. 252 s.) dificulta bastante deslindar los ámbitos respectivos de responsabilidad pública y privada: desde que la omisión es un simple hecho físico, no excluye que ella sea siempre, en definitiva, la traducción de una falta personal. 
38. Ahora bien, esta esquematización parece largamente indiferente a la presencia de un órgano. El art. 42 no conserva trazas de la teoría del órgano, ni siquiera si se interpretan estas nociones de falta de servicio y falta personal a la luz de la teoría.

Para que la responsabilidad directa del art. 42 dependiese de la teoría del órgano sería preciso que el órgano nunca fuese capaz de comprometer una responsabilidad distinta. Es esa premisa la que no puede extraerse del derecho positivo. Porque el art. 4 dispone que contra el órgano caben acciones de repetición y porque el art. 42 aplica esta regla al caso de la falta personal, resulta que el órgano no siempre compromete en forma única y exclusiva la responsabilidad del Estado. Según la ley, en algunos casos el órgano puede comprometer una responsabilidad distinta del Estado: la suya propia, en caso de falta personal. La definición del patrimonio responsable no depende, entonces, de la intervención de un órgano en el hecho dañoso.

Más allá de la pura exégesis, parece sensato pensar que la ley no travistió la realidad al extremo. Ella reconoció que el dato inicial en la responsabilidad pública por culpa (aquella regida por el art. 42) es justamente el hecho de un hombre, hecho que admite calificaciones diversas por el juez. Es cierto que el art. 42 no rechaza la posibilidad de que la falta de servicio sea un hecho "del" servicio o del órgano (la "culpa difusa"), pero desde que la falta personal también es hecho de un funcionario, el simple carácter de órgano del hechor no da certeza suficiente acerca del contenido de la falta de servicio.

39. Sería de poca utilidad intentar salvar a la teoría mediante el recurso a Hauriou. Podría ser tentador, en efecto, recurrir a este autor, en cuanto él aceptaba como elemento definitorio del órgano (y, por consiguiente, de la falta de servicio) el hecho de que el funcionario se mantuviera "en la línea de la función". 55 Pero esta prevención parece, más que una rectificación de la teoría, su sustitución por un criterio funcional. ${ }^{56}$ No obstante, se ha visto que el ejercicio de funciones por parte del agente es simple condición de la obligación a la deuda por el patrimonio público, sin identificar una responsabilidad directa, según el art. 4. De este modo, la definición de una responsabilidad directa pasa necesariamente por una conceptualización adecuada de las nociones de falta de servicio y falta personal. En este contexto, la falta de servicio podría ser definida, no sobre la base de la calidad del órgano del autor del daño, ya que todo funcionario la posee, sino por la intensidad con que su hecho se identifica con la función. Sin embargo, la Ley misma no suprimió la posibilidad de que la jurisprudencia, si quisiera hacer realidad la regla de responsabilidad por faltas personales, indague la existencia de estas faltas aún entre los hechos cometidos por el funcionario en ejercicio de sus funciones; es más, tal ejercicio podría aparecer legitimado, dentro de la Ley, si

\footnotetext{
${ }^{55}$ Hauriou, M., Précis de droit administratif et de droit public, $7^{\mathrm{a}}$ ed., 1911, op. cit., p. 492.

${ }^{56}$ Un autor uruguayo adhiere a la idea de que el acto de un hombre se imputa al órgano "en tanto pueda considerarse que existe desarrollo de función pública por parte del funcionario”. Frugone, H., "Introducción al estudio de la organización administrativa. Bases para una teoría del órgano”, en AAVV, La Contraloría General de la República. 50 años de vida institucional (1927-1977), Universidad de Chile - Facultad de Derecho, Departamento de Derecho Público, Santiago, 1977, p. 55 s. (esp:, p. 68).
} 
se constata la existencia de hechos que una disciplina jurídica atenta a la moralidad o probidad de los agentes públicos aconseje dejar su cargo.

40. El análisis precedente versa principalmente sobre la Ley de Bases. Puede parecer que ese análisis descuide la jurisprudencia. De hecho, la jurisprudencia no se preocupa demasiado de la estructura legal de la responsabilidad, básicamente por instigación de la doctrina. En la jurisprudencia, el carácter directo de la responsabilidad del Estado es estadísticamente abrumador. Este carácter directo no reposa, en realidad, sobre consideraciones orgánicas; arranca más bien de un razonamiento circular: una convicción respecto de la autonomía u originalidad del derecho público de la responsabilidad, que descartaría una responsabilidad indirecta o por hecho ajeno que obligue a analizar la culpa del funcionario. Estadísticamente, la falta personal es prácticamente inexistente en jurisprudencia, a pesar de que la ley la ha reconocido explícitamente para fundar una responsabilidad indirecta.

\section{b. La responsabilidad pública indirecta}

41. Una parte importante de la responsabilidad de la administración está articulada como una responsabilidad por hecho propio, es decir, una responsabilidad directa. Sin embargo, no toda responsabilidad pública es directa; la responsabilidad pública no es, por tanto, intrínsecamente directa.

Si en verdad se tratara de una responsabilidad por hecho propio del Estado, ¿por qué subsiste una responsabilidad personal del funcionario? El art. 4 de la Ley de Bases prevé explícitamente esta responsabilidad personal, como otros textos lo recuerdan a propósito de las faltas personales (art. 42, aparte de la Ley de Municipalidades, entre otros). Estos textos están ahí para recordar que la teoría del órgano nunca es más que un artificio, ingenioso quizá, pero en definitiva ficticio. El Estado responde, pero eso no borra (todas) las responsabilidades personales del funcionario autor del hecho.

42. Esta observación es estrictamente cierta en todo cuanto concierne los aspectos represivos del derecho: la responsabilidad disciplinaria nunca queda absorbida por la responsabilidad pecuniaria del Estado; la responsabilidad penal, es bien sabido, no desaparece tras una indemnización (pagada, por lo demás, por alguien que no es el infractor personal).

Sin necesidad de analizar (por ahora) la situación de la responsabilidad civil, la conclusión preliminar que estos desarrollos imponen consiste en que es perfectamente posible que el acto de un hombre sea considerado como un acto del Estado, pero nada impide que las consecuencias de ese acto sean distribuidas entre el hombre y el Estado. ${ }^{57}$

${ }^{57}$ Es precisamente mediante la observación de la dicotomía de tratamiento entre las responsabilidades civiles y penales que Jean Guyénot expresa su perplejidad frente a la teoría del órgano. La responsabilité des personnes morales publiques et privées. Considérations sur la nature et le fondement de la responsabilité du fait d'autrui, LGDJ (col. Bibliothèque de la Faculté de droit et de sciences économiques de l'Université d'Alger), París, 
43. Caldera mismo lo reconoció, aunque en términos bastante contradictorios, al decir que la responsabilidad "directa" del Estado no impedía que el hecho pudiera, simultáneamente, comprometer la responsabilidad disciplinaria, civil o penal del funcionario frente al Estado. ${ }^{58}$

44. En verdad, es el art. 4 de la Ley de Bases quien reconoce esta responsabilidad indirecta del Estado y las personas públicas. La responsabilidad que pueda incumbirles es sin perjuicio de la que afecte eventualmente al funcionario que hubiere ocasionado el daño.

Con esa reserva, la Ley no se refiere en absoluto a los hechos que el funcionario (u órgano) cometa fuera del ejercicio de sus funciones, pues en ese evento según la ley misma el patrimonio público no soporta ninguna responsabilidad. Se refiere, en cambio, a responsabilidades eventuales del agente público por hechos cometidos en ejercicio de sus funciones.

Aquí las relaciones entre imputación y órgano se complican. Ni el ejercicio de funciones ni el estatus de órgano del agente determinan que el patrimonio responsable sea estatal, porque los actos que el funcionario ejecuta incluso en ejercicio de sus funciones pueden, en atención a las circunstancias e independientemente de su imputación al servicio, permanecer como imputables al agente.

Bien pensado, sería incoherente con la intensidad de la imputación que el órgano apareja, que esta responsabilidad indirecta se fundara en el órgano: significaría que un órgano del Estado puede comprometer la responsabilidad de una persona diversa.

En síntesis, la teoría del órgano no define los caracteres de la responsabilidad.

Varios de los casos de subsistencia de una responsabilidad personal del funcionario pueden resolverse mediante el concepto de falta personal, sea que comprometan simultáneamente o no la responsabilidad del patrimonio público. Como comienza a decir la jurisprudencia, la ley "no excluye la [responsabilidad] que pueda ser consecuencia de una falta personal del agente público cuya acción u omisión provoca el perjuicio indemnizable". 59 Para comprender este mecanismo de responsabilidad indirecta, parece ineludible abordar una conceptualización más fina de la falta personal, tarea que sigue pendiente en el medio nacional.

45. Interesa destacar dos aspectos de lo que va dicho hasta aquí. La extensión de la responsabilidad pública indirecta o por hecho ajeno no depende de consideraciones or-

1959, § 114 s., p. 89 s. Estas observaciones, quizá superadas en cuanto concierne a la responsabilidad penal de las personas jurídicas, conservan aún fuerza explicativa, en Francia, respecto de la persona Estado (que sigue siendo incapaz de cometer culpa penal).

${ }^{58}$ RDP-UCh N $\mathrm{N}^{\circ}$ 25-26, op. cit., p. 160 s.; Sistema, op. cit., p. 195.

59 Así consta de las decisiones CS, 19.10.2005, Caro Silva c/ Fisco y 20.03.2006, Vargas Grandón cl García Hernández, precitadas, declaración que por intervenir en materia de fuerzas policiales cobra mayor relevancia. Por otra parte, el fallo Vargas Grandón añade que el art. 4 de la Ley de Bases recoge así "la misma noción que se consigna en el inciso segundo del artículo 38 de la Carta Política Nacional”. 
gánicas (i); más aún, la autonomía de las soluciones del derecho público en este terreno no depende de consideraciones orgánicas (ii).

\section{(i) Extensión de la responsabilidad por hecho ajeno}

46. Al definir la responsabilidad del Estado en función de los hechos cometidos en ejercicio de las funciones públicas, la Ley da la espalda a la teoría del órgano.

Hugo Caldera parece haberse anticipado a este problema (sus reflexiones son anteriores a la Ley de Bases), manifestando que para comprometer la responsabilidad del Estado basta una relación cualquiera entre el agente y el servicio o el órgano públicos. ${ }^{60}$ Ni elegante ni mucho menos precisa, la fórmula ha hallado cierta acogida en la jurisprudencia. ${ }^{61}$ Sin embargo, ella no resulta de la teoría del órgano ni del derecho escrito, sino refleja una posición particular (aunque no original) de su autor.

De los textos, en primer lugar, ella se aleja, pues éstos disponen la responsabilidad por hechos cometidos por los órganos en ejercicio de sus funciones, es decir, exige bastante más que una relación cualquiera. Con respecto a la teoría, en seguida, la fórmula pone en evidencia su insuficiencia. En realidad, si un vínculo orgánico fuese necesario para comprometer la responsabilidad pública, toda actuación del agente (órgano) la conllevaría; sería inútil recurrir a este criterio auxiliar del vínculo con la función. ${ }^{62}$

En definitiva, la afirmación del autor puede ser verdadera o falsa, pero en cualquier caso es independiente de la teoría del órgano. Es, si se quiere, una afirmación arbitraria, en cuanto su sentido no puede verificarse a la luz de sus postulados.

47. Que tal afirmación consagre una solución plausible o incluso justa, esa es una valoración diversa. Por cierto, la extensión de la responsabilidad a estos casos, operada por vía puramente jurisprudencial, parece un logro importante en la medida que conduce a extender las soluciones legales más allá de su texto. Esta solución parece justificarse

60 "Para que la responsabilidad tenga lugar y para que nazca el derecho de la víctima a ser indemnizada es suficiente que la actuación del agente público esté relacionada con el servicio u órgano público...”. RDP-UCh N 25-26, op. cit., p. 167; Sistema, op. cit., p. 206.

${ }^{61}$ V. p. ej., CA Santiago, 21.09.1995, Béraud c/ Fisco (cons. 37), precitado; CA Valparaíso, 15.04.2002, c/ SS Viña del Mar-Quillota (cons. 2), precitado; CA Copiapó, 28.06.2002, c/ Pereira Ortiz (cons. 14), conf. CS (forma), 30.10.2002, GJ No 268, 2002, p. 133, CS (fondo), 02.06.2004, Rol n².868-2002; CA Santiago, 01.07.2003, Bustos c/ Fisco, GJ N ${ }^{\circ}$ 277, 2003, p. 149 (cons. 10), conf. CS, 26.01.2005, GJ No 297, 2005, p. 58; CA San Miguel, 29.08.2003, cl Concha Orellana (cons. 27, para una ligera variación), precitado; y las decisiones también citadas del 18 JLCiv Santiago, 22.10.1999, Vargas Vargas c/ Fisco (cons. 12), y del 7 JLCiv. Santiago, 31.05.2004, Flores Gálvez cl Fisco (cons. 10); 08.06.2004, Tognola Canales c/ Fisco (cons. 8); 29.07.2004, Parada Muñoz c/Fisco (cons. 13). Debe tenerse presente que, de todos estos casos, la afirmación parecía necesaria sólo en el asunto Bustos.

${ }^{62} \mathrm{~J}$. Guyénot señala en cambio que la teoría "no permite garantizar la seguridad de los terceros frente a las acciones nocivas de los dependientes de una persona jurídica. Directamente responsable, ésta no puede responder por las culpas incompatibles con la misión que ella ha confiado al órgano”. Op. cit., § 116, p. 90 s. En cualquier caso, la insuficiencia de la teoría del órgano sigue siendo manifiesta; para este autor, un modelo de responsabilidad por otro parece preferible a las limitaciones de una responsabilidad "orgánica”. 
ampliamente por consideraciones diversas a la teoría del órgano: es una cuestión de coherencia del derecho (o de equidad, si se quiere) lo que conduce a la jurisprudencia a extender la responsabilidad a estos casos de un simple vínculo con las funciones (y no ya de ejercicio de funciones). Resultaría chocante, en efecto, que en hipótesis de ilícitos personales de los agentes, pero vinculados con el servicio, el Estado se desentendiera de toda responsabilidad, en circunstancias que éste responde del ejercicio de sus funciones. ${ }^{63}$ Parecería contrario a toda equidad, por ejemplo, que el Estado no responda cuando un cabo del ejército dispara sobre un recluta del servicio militar con un arma que le ha sido facilitada regularmente por el servicio, ${ }^{64}$ en circunstancias que debería responder sin lugar a dudas si el cabo ha podido apoderarse del arma por una insuficiente vigilancia en su custodia.

En todo caso, esta extensión de la responsabilidad, como el cúmulo de responsabilidades en los tiempos de Hauriou, es prueba suficiente de la incapacidad de la teoría del órgano para explicar el conjunto de la responsabilidad pública.

\section{(ii) La autonomía de la responsabilidad pública}

48. En segundo lugar, la existencia de una responsabilidad pública indirecta deja en evidencia una derogación, tácita y parcial, de las reglas del Código civil sobre la responsabilidad extracontractual.

Que el Estado deba responder de todos los hechos cometidos en servicio por sus funcionarios implica necesariamente que él absorbe una parte de las culpas que éstos puedan cometer. Por cierto, no las absorbe todas, pues el art. 4 prevé la posibilidad de un recurso contra el funcionario aun en caso de daños causados en ejercicio de sus funciones.

El art. 4 de la Ley de Bases no entrega pistas para determinar en qué forma se produce esta derogación; en cambio, los conceptos de falta de servicio y de falta personal recogidos por el art. 42 suministran una base más precisa para resolver estas materias. Independientemente de la noción que se tenga de estos conceptos, la existencia de una responsabilidad pública que no obsta a la subsistencia de responsabilidades individuales de sus funcionarios deja en evidencia que el Código civil puede formalmente seguir rigiendo parcialmente algunas hipótesis de responsabilidad en caso de hechos cometidos por el funcionario.

${ }^{63}$ Reflexiones de este género llevaron a Gastón Jèze a justificar la extensión de la responsabilidad pública. Cf. su nota sobre el arrêt Tribunal des Conflits, 02.05.1914, Provost et Cornu, en Revue du droit public 1914, p. 569: "La exclusión de la responsabilidad del patrimonio administrativo continuaba en este caso [de falta personal] reposando sobre la irresponsabilidad administrativa general del Estado. Ya se descartó el principio de la irresponsabilidad del Estado por los casos de falta de servicio; se lo ha mantenido para el caso de falta personal. Esto es ilógico".

${ }^{64}$ Para una hipótesis similar, v. el fallo antes citado Bustos c/Fisco, aunque en este caso la jurisprudencia decidió resolver el asunto por la falta de servicio (Corte de Apelaciones) y después aplicando una responsabilidad por riesgo (Corte Suprema). Cf. Valdivia, J. M., "Nuevas fronteras de la falta de servicio", en $G J \mathrm{~N}^{\circ} 301,2005$, p. 7. 
Como ha quedado dicho, la Ley no excluye por sí misma que el hecho de un órgano sea calificado como falta personal y haga surgir una responsabilidad individual (civil) independiente -o coetánea- de la responsabilidad pública. El carácter de órgano del agente no consigue determinar en qué medida el Código civil ha sido derogado o sigue subsistente respecto de los funcionarios públicos.

49. A la luz de estas reflexiones, pareciera necesario revisar la afirmación según la cual la cuestión de las culpas de los funcionarios sólo tiene incidencia en el plano interno de los servicios. Esa concepción de la responsabilidad administrativa como impermeable a la culpa no está recogida por la Ley de Bases, que descansa, en buena medida, en la distinción entre falta personal y falta de servicio, asumiendo que las relaciones de imputación de los actos de los agentes públicos a las personas públicas son de intensidad variable.

La cuestión de las culpas de los agentes no es, tampoco, un aspecto puramente interno al servicio. Tratándose de las faltas de servicio, en la medida que estas culpas son absorbidas integralmente por el servicio, no hay ningún aspecto interno en que la culpa pueda tener incidencia (a menos que una falta personal se acumule, o provoque, incluso, la falta de servicio). El Estado (o la persona pública de que se trate) no puede repetir en contra de su agente, porque el acto deja de serle imputable. Ciertamente, el organismo podrá intentar establecer una disciplina interna, por vía normativa por ejemplo, a fin de evitar la reedición de los incidentes que generaron la responsabilidad, o investigar y sancionar eventualmente responsabilidades disciplinarias. Pero desde el punto de vista civil no hay nada que hacer. Y en cambio, tratándose de las faltas personales puras, aquellas culpas civiles absolutamente desligadas del servicio, cometidas fuera de las funciones, aunque la ley siga atribuyéndolas al "órgano", el servicio no responde por ellas y con mayor razón no dan origen a ninguna relación ínterorgánica.

\section{CONCLUSIÓN}

50. Resulta difícil explicar la tentativa de articular la responsabilidad pública en torno a la teoría del órgano. Puede avanzarse la tesis de que, al buscarse una nomenclatura arcana, que reconducía a secretos propios del derecho público, se aseguraba cierta autonomía o especificidad de soluciones para esta área del derecho. Esa posición podría sostenerse si se conservasen vestigios de una reflexión suficiente en torno a la teoría del órgano. Como nada de eso hay, la invocación de la teoría parece puramente arbitraria.

En cualquier caso, la teoría no encierra ninguna regla de responsabilidad que permita definir un régimen de responsabilidad. Sólo concierne la imputación de ciertos actos a una persona jurídica. Desde ese punto de vista, la teoría es neutra a efectos del régimen de responsabilidad aplicable. Es una teoría elástica, que no coincide con los resultados a que lleva el derecho positivo de la responsabilidad. En el mejor de los casos, nada agrega al derecho positivo de la responsabilidad. No se ven las razones para seguir complicándose con una esquematización teórica que no presenta ninguna utilidad. 
La teoría no explica el carácter directo de la responsabilidad. Como decía Chapus, o bien "la responsabilidad de la persona jurídica es directa porque es verdaderamente una responsabilidad por hecho propio, y entonces chocamos con lo inverosímil", o bien "la responsabilidad es directa porque decidimos que así lo sea". ${ }^{65}$ La teoría del órgano, que se supone evita el recurso a más y más ficciones, se revela como una superchería poco cré́ble, insuficiente para explicar todas las sutilezas de la materia. ${ }^{66}$

Por otra parte, la teoría del órgano es incapaz de definir los casos de responsabilidad indirecta, que proporcionan una garantía innegable para el ciudadano.

El derecho público de la responsabilidad presenta una responsabilidad directa y una responsabilidad indirecta. Fundar esta diferencia en la noción de órgano consiste en decir que en ciertos casos el órgano del Estado no actúa por el Estado o no forma parte de él, sin que la teoría del órgano proporcione indicios de solución para esta dicotomía. ${ }^{67}$

\section{BIBLIOGRAFÍA}

Alessi, R., La responsabilità della pubblica amministrazione, Giuffrè, Milán, 1939.

Auby, J.-B., La notion de personne publique en droit administratif, Burdeos (tesis), 1979.

Beaud, O., La puissance de l'État, París, PUF (coll. Léviathan), 1994.

Caldera, H., "Teoría del órgano, Estado de derecho y responsabilidad del Estado: notas sobre su formulación en el derecho chileno", RDP-UCh No 25-26, 1979.

Carré de Malberg, R., Contribution à la théorie générale de l'État. Spécialement d'après les données fournies par le droit constitutionnel français, Sirey, París, 1922 (reedición Dalloz, París, 2004).

Cassese, S., Le basi del diritto amministrativo, Garzanti, Milán, $3^{a}$ ed., 1995.

Cassese, S. (dir.), Tratato di diritto amministrativo, Giuffrè, Milán, 2000.

CHapus, R., Responsabilité publique et responsabilité privée. Les influences réciproques des jurisprudences administrative et judiciaire, LGDJ (col. Bibliothèque de droit public), París, 1954.

Crisafulli, V., "Alcune considerazioni sulla teorie degli organi dello Stato", en Archivio giuridico $\mathrm{N}^{\circ} 120,1938$.

Crosetti, A., "Organi”, en Digesto delle discipline pubblicistiche, UTET, Turín, $4^{a}$ ed., 1995.

Duguit, L., L'État, les gouvernants et les agents, Fontemoing, París, 1903 (reedición Dalloz, París, 2005).

Esposito, C., "Organo, ufficio e soggettività dell'ufficio", Annali dell'Università di Camerino, 1932, repr. en Esposito, C., Scritti giuridici scelti, II, Teoria generale dello Stato e Diritto costituzionale prerepubblicano, Jovene, Nápoles, 1999.

Forsthoff, E., Traité de droit administratif allemand, Bruselas, Bruylant, trad. por M. Fromont, 1969.

${ }^{65}$ Responsabilité publique et responsabilité privée, op. cit., \$ 196.

${ }^{66}$ La sola existencia de la acción de retorno de la persona jurídica contra su órgano revela la incongruencia de la teoría. Así, Sabourin, P., op. cit., p. 219 s.; cf. Auby, J.-B., La notion de personne publique en droit administratif, Burdeos (tesis), 1979, p. 215.

${ }^{67}$ La cuestión, antigua pero nunca resuelta en forma satisfactoria, es uno de los flancos más conocidos de la crítica de Cassese, S., op. cit., p. 157. 
Galgano, F., Delle persone giuridiche, en Scialoja, A. y Branca, G., Commentario del Codice civile, Zanichelli-Foro Italiano, Bolonia-Roma, 1969.

Giannini, M. S., "Organi (teoria generale)", Enciclopedia del diritto, t. 31, Giuffrè, Milán, 1981.

Giannini, M. S., Diritto amministrativo, Giuffrè, Milán, $3^{a}$ ed., 1993.

GuYÉNOT, J., La responsabilité des personnes morales publiques et privées. Considérations sur la nature et le fondement de la responsabilité du fait d'autrui, LGDJ (col. Bibliothèque de la Faculté de droit et de sciences économiques de l'Université d'Alger), París, 1959.

Hauriou, M., Précis de droit administratif et de droit public, Sirey, París, $6^{a}$ ed., 1907; $7^{a}$ ed., 1911; $8^{a}$ ed., 1914; $9^{a}$ ed., 1919; $10^{a}$ ed., 1921; 12a ed., por A. Hauriou, 1933 (reedición Dalloz, París, 2002).

Illanes, C., "Responsabilidad civil del Estado y de sus dependientes", Revista de Derecho-U. Católica del Norte $\mathrm{N}^{\circ}$ 6, 1999.

Kelsen, H., Théorie générale du droit et de l'État, LGDJ-Bruylant, París-Bruselas, trad. B. Laroche, 1997.

Michoud, L., La théorie de la personnalité morale et son application au droit français, LGDJ, París, $2^{a}$ ed. por L. Trotabas, 1924.

SABOURIN, P., Recherches sur la notion d'autorité administrative en droit français, LGDJ (col. Bibliothèque de droit public), París, 1966.

SANTAmaría, J. A., "Órgano administrativo", en Nueva enciclopedia jurídica, t. 18, Seix, Barcelona, 1986. 